\title{
Encapsulação de compostos bioativos por coacervação complexa
}

\author{
Encapsulation of bioactive compounds by complex coacervation
}

Thaiane Marques da Silva ${ }^{1}$, Luiza Zancan Rodrigues ${ }^{2}$, Graciele Lorenzoni Nunes ${ }^{3}$, Cristiane Franco Codevilla ${ }^{3}$, Cristiane Bona da Silva ${ }^{3}$, Cristiano Ragagnin de Menezes ${ }^{4}$

\author{
${ }^{1}$ Mestranda em Ciência e Tecnologia dos Alimentos, Universidade Federal de Santa Maria, RS, Brasil \\ thaianemsilva@hotmail.com \\ ${ }^{2}$ Graduanda em Tecnologia em Alimentos Universidade Federal de Santa Maria, RS, Brasil \\ luiza.zanca.r@hotmail.com \\ ${ }^{3}$ Doutora em Ciências Farmacêuticas, Universidade Federal de Santa Maria, RS, Brasil \\ graci_nunes@hotmail.com; cristianefc@hotmail.com; cristie.bona@gmail.com \\ ${ }^{4}$ Doutor em Ciência de Alimentos, Universidade Federal de Santa Maria,RS, Brasil \\ cristiano.ufsm@gmail.com
}

\begin{abstract}
Resumo
Os compostos bioativos são substâncias químicas presentes em plantas e são amplamente conhecidos por trazerem beneficios à saúde, assim podendo ser designados como alimentos funcionais. Entretanto, são sensíveis a vários fatores encontrados no meio em que estão expostos, principalmente ao tratogastrointestinal e, além disso, são lipofílicos, assim, apresentam baixa solubilidade em meios aquosos. Nesse sentido, a encapsulação desses compostos surge como uma alternativa de proteção, bem como de fornecimento desses compostos em quantidades adequadas. A coacervação complexa é uma técnica de microencapsulação muito utilizada para esses compostos, além de apresentar vantagens frente a outras técnicas, como a utilização de biopolímeros, não utilização de agentes tóxicos, entre outros. Atualmente, existem muitas pesquisas nesse sentido, as quais serão apresentadas no decorrer deste trabalho. Dessa forma, o presente artigo de revisão tem como objetivo apresentar os principais compostos bioativos estudados e encapsulados, bem como os parâmetros referentes à técnica de coacervação complexa.
\end{abstract}

Palavras-chave: Compostos bioativos. Alimentos funcionais. Encapsulação. Coacervação complexa.

\begin{abstract}
The bioactive compounds are chemicals found in plants and are widely known for bringing health benefits, so it can be designated as functional foods. However, they are sensitive to various factors found in the environment that are exposed primarily to tratogastrointestinal and, moreover, are lipophilic, therefore, have low solubility in aqueous media. In this sense, the encapsulation of these compounds is an alternative protection, and the provision of such compounds in suitable amounts. The complex coacervation microencapsulation is a technique commonly used for such compounds, besides having front advantages to other techniques such as the use of biopolymers, no use of toxic agents, among others. Currently, there are a lot of research in this direction, which will be presented in this paper. Thus, the present review aims to present the main bioactive compounds studied and encapsulated as well as the parameters for complex coacervation technique.
\end{abstract}

Keywords: Bioactive compounds. Functional foods. Encapsulation. Complex coacervation. 


\section{Introdução}

O termo compostos bioativos refere-se a um grupo de compostos produzidos pelas plantas, os quais exibem significativas propriedades biológicas, como, atividade antioxidante, antimicrobiana, anti-inflamatória e anti-tumoral, com grande potencial de exploração nas indústrias farmacêuticas, alimentícias e químicas. Estes compostos variam muito em termos de estrutura e função química e estão agrupadas em conformidade. Os compostos bioativos podem ser encontrados principalmente em frutas, vegetais, cereais, oleaginosas e óleos, como por exemplo, maçãs, frutas cítricas, uvas, cebolas, cenouras, tomates, alhos, feijões, cacau, soja, semente de gergelim, semente de algodão, amendoins, semente de mostarda, arroz, arroz selvagem, folhas de cevada e aveia (KRISETHERTON et al. 2002; SECOLIN, 2014).

Atualmente, o desenvolvimento de alimentos funcionais por meio da adição de compostos bioativos detém muitos desafios tecnológicos. Muitos compostos bioativos são altamente lipofílicos e, consequentemente, apresentam baixa solubilidade em água, o que faz com que sua adição na maioria dos alimentos seja dificultada. Além disso, a baixa solubilidade, também significa menor absorção no trato gastrointestinal e, por conseguinte, sua biodisponibilidade torna-se limitada. Assim, na indústria alimentar, tornou-se evidente a necessidade imediata no desenvolvimento de sistemas para proteger e liberar os compostos bioativos presentes nos alimentos funcionais (CHAMPAGNE; FUSTIER, 2007; DONSİ et al., 2011).

Dessa forma, uma alternativa frente a esses fatores e para aumentar a estabilidade dos compostos bioativos em condições ambientais adversas (temperatura, luz e oxigênio), como na estocagem e processamento, e preservar sua atividade antioxidante, consiste na técnica de microencapsulação. A microencapsulação consiste no empacotamento de materiais sólidos, líquidos ou gasosos em cápsulas extremamente pequenas. Esta técnica oferece, além de proteção ao material encapsulado, a possibilidade de liberá-lo de forma controlada sob condições específicas (FÁVARO-TRINTADE et al., 2008).

A coacervação complexa é utilizada principalmente para microencapsular substâncias hidrofóbicas e consiste, basicamente, na combinação de duas soluções hidrocolóides de cargas opostas causando interação e precipitação dos polímeros complexos, que resultará na formação de microcápsulas. Além disso, a coacervação complexa apresenta algumas vantagens frente a outras técnicas, como a possibilidade de se trabalhar com biopolímeros, a ausência de solvente orgânico e as condições brandas de temperatura no processamento, possuindo assim, características adequadas para a encapsulação de compostos bioativos (ASSIS et al., 2012; ALVIM; GROSSO, 2010; SHOJI et al., 2013)

Diante do exposto, esse artigo de revisão tem por objetivo abordar os aspectos relacionados aos compostos bioativos e a sua encapsulação por meio da técnica de coacervação complexa.

\section{Compostos bioativos}

Os alimentos que promovem benefícios à saúde (além de seu valor nutritivo) ou que tenham um papel na prevenção do risco de doenças são denominados alimentos funcionais. Os componentes benéficos presentes nos alimentos funcionais podem ser designados, entre outras terminologias, como compostos bioativos. Estes componentes exercem seus efeitos agindo como antioxidantes, ativando enzimas de desintoxicação do fígado, bloqueando a atividade de toxinas bacterianas ou virais, inibindo a absorção de colesterol, diminuindo a agregação de plaquetas, ou destruindo bactérias gastrointestinais prejudiciais. Estes compostos bioativos incluem lipídios, vitaminas, peptídeos, ácidos graxos, antioxidantes, minerais e células vivas, tais como probióticos. Há aproximadamente 120 alimentos naturais identificados que contêm compostos bioativos e poderiam, portanto, ser designados como funcionais. Na Tabela 1 serão apresentados alguns desses alimentos (PENNINGTON, 2002; DE VOS et al., 2010).

Os compostos bioativos incluem uma variedade de compostos químicos com estruturas variadas, tais como carotenóides, flavonóides, esteróis vegetais, ácidos graxos ômega-3 (n-3), alil e dialil sulfetos e ácidos fenólicos. De acordo com a legislação brasileira algumas destas substâncias bioativas já possuem 
alegação de propriedade funcional aprovada: ácidos fenólicos, ácidos graxos (monoinsaturados $\omega-3$ e $\omega-6$ ), beta glucana, carotenoides (licopeno, luteína, zeaxantina), dextrina resistente, fitoesteróis, frutooligossacarídeos (FOS), goma guar parcialmente hidrolisada, inulina, fibras alimentares, fitoesteróis, lactulose, polidextrose, polióis (manitol, sorbitol, xilitol), probióticos, proteína de soja, Psillium (Plantago ovatae), quitosana (PENNINGTON, 2002; ANVISA, 2008).

Atualmente, o efeito da utilização dos compostos bioativos na alimentação já pode ser

Tabela 1 - Exemplos de alimentos designados como funcionais (e alguns dos seus componentes bioativos)

Frutas e Vegatais

Frutas cítricas

Maçãs

Morango

Uvas vermelhas/suco de uva

Alface

Alho

Azeitona

Brócolis

Cenoura

Couve

Espinafre

Feijões

Tomate

Oleaginosas

Amendoins

Cacau

Sementes de gergelim

Soja

Cereais

Arroz

Aveia

Milho observado em pessoas que fazem uso desses compostos de forma regular, ou seja, habitual, como por exemplo, a população asiática, cujo hábito alimentar de consumir soja em quantidades muito superiores às normalmente consumidas em outras regiões, poderia reduzir os riscos da osteoporose; ou mesmo, da população do mediterrâneo, cuja alimentação mais rica em frutas, verduras, azeite de oliva e vinho tinto poderia reduzir o risco de doenças cardiovasculares, câncer e obesidade, dentre outros (COZZOLINO, 2012).

Naringenina, hesperetina, hesperidina, naringina, ácido p-cumárico, ácido caféico, ácido ferúlico

Quercetina, epicatequina, ácido clorogênico, ácido pcumárico, floridzina

Antocianinas, flavanóis (procianidinas), flavonóis (quercetina); ácidos fenólicos (ácido clorogênico, ácido elágico, ácido p-cumárico); beta-sitosterol

Antocianinas, flavanóis (catequinas, procianidinas), flavonóis (quercetina, miricetina); ácidos fenólicos (ácido elágico); beta-sitosterol; resveratrol

Flavonóis (quercetina, campferol); beta-sitosterol, campesterol, estigmasterol

Alil/dialil sulfetos (alicina); saponinas

Beta-criptoxantina

Beta-caroteno, beta-criptoxantina, luteína; flavonóis (quercetina, campferol); indol

Alfa-caroteno, beta-caroteno, licopeno; ácidos fenólicos (ácido clorogênico, ácido p-cumárico); beta-sitosterol, campesterol, estigmasterol

Luteína, zeaxantina; indol

Beta-caroteno, luteína, zeaxantina; flavonas, flavonóis

Antocianinas, flavonóis, isoflavonas

Beta-caroteno, beta-criptoxantina, licopeno; (flavonóis quercetina), produtos de flavanonas (naringenina); ácidos fenólicos (ácido p-cumárico, ácido clorogênico

Beta-sitosterol, campesterol, estigmasterol

Taxifolina

Catequina, epicatequina; ácido clorogênico

Sesamol, sesaminol, tocoferol, sesamolinol

Isoflavonas (genisteína, daidzeína, daidzina, genistina, glicitina, coumesterol); beta-sitosterol, campesterol, estigmasterol

Orizanol, isovitexina, cianidina-3- $\beta$-D-glicopiranosídeo, pinoresinol, outros compostos fenólicos

Ésteres de ácidos caféicos e felúricos Beta-criptoxantina, zeaxantina; flavanóis (procianidinas) 


\section{Encapsulação de compostos bioativos}

A microencapsulação pode ser definida como uma tecnologia de empacotamento de materiais sólidos, líquidos ou gasosos, formando cápsulas que podem liberar seus conteúdos a taxas controladas e em condições específicas, podendo ser utilizadas industrialmente com o intuito de aumentar a utilização dos compostos bioativos nos produtos disponíveis no mercado. Dessa forma, esta técnica tem sido aplicada a vários segmentos, como por exemplo, indústrias farmacêuticas, de cosméticos e de alimentos. Recentemente, a microencapsulação é uma ferramenta útil para melhorar a disponibilidade de compostos bioativos em alimentos, especialmente probióticos, minerais, vitaminas, fitoesteróis, luteína, ácidos graxos, licopeno e antioxidantes (CHAMPAGNE; FUSTIER, 2007; SIEGRIST et al., 2007; DE VOS et al., 2010; SAUVANT et al., 2012; SECOLIN, 2014).

No entanto, uma característica limitante dos compostos bioativos presentes nos alimentos, é que estão sujeitos à rápida inativação ou degradação. Muitos desses compostos, portanto, podem ser beneficiados pela encapsulação que retarda e/ou evita os processos de degradação até o produto ser consumido (DE VOS et al., 2010).

Dessa forma, recentemente, grande atenção tem sido direcionada a microencapsulação, pois a eficácia dos produtos nutracêuticos, como os compostos bioativos, na prevenção de doenças depende da preservação da biodisponibilidade dos ingredientes ativos. Este é um grande desafio, pois várias limitações precisam ser superadas, uma vez que apenas uma pequena proporção das moléculas permanecem disponíveis após administração oral, devido ao tempo insuficiente de permanência em condições gástricas, a baixa permeabilidade e/ou solubilidade no intestino, bem como a sua instabilidade sob condições encontradas no processamento e no armazenamento dos alimentos (temperatura, oxigênio, luz), ou no trato gastrointestinal ( $\mathrm{pH}$, enzimas, presença de outros nutrientes) e a liberação controlada, além de muitas substâncias presentes nos alimentos poderem interferir com a bioatividade do composto, os quais limitam a atividade e os potenciais benefícios a saúde trazidos pelos componentes bioativos, além de problemas de instabilidade como reações de autooxidação, epimerização e baixa disponibilidade. Por conseguinte, é imperativo que o processo de encapsulamento proteja o composto bioativo durante todo o período de processamento, armazenamento, e transporte (DE VOS et al., 2010; FANG; BHANDARI, 2010; SECOLIN, 2014).

Além disso, é importante ressaltar que apesar da microencapsulação aumentar a dispersão dos compostos pouco solúveis em água, não deve alterar as propriedades sensoriais, como a cor e o sabor dos produtos alimentícios (SAUVANT et al., 2012).

Ademais, muitos procedimentos de encapsulação têm sido propostos, mas nenhum deles pode ser considerado como um processo universalmente aplicável para os compostos bioativos. Isto se deve ao fato de que esses compostos têm a sua própria estrutura molecular característica. Eles demonstram enormes diferenças em termos de peso molecular, polaridade, solubilidade, entre outros, o que implica que diferentes abordagens de encapsulação têm de ser aplicadas, a fim de satisfazer os requisitos físico-químicos e moleculares específicos para cada composto bioativo (BETORET et al., 2011; DE VOS et al., 2010).

No entanto a compatibilidade da técnica com o composto bioativo não é o único requisito que um processo de encapsulação tem de satisfazer. Ele também deve ter características específicas para resistir às condições externas (BETORET et al., 2011).

Portanto, o desenvolvimento de mecanismos de proteção que possam manter a estabilidade dos compostos naturais ativos até o momento do consumo, bem como proporcionar um sistema de liberação alvo fisiológico específico são de fundamental importância (SECOLIN, 2014).

\subsection{Principais técnicas utilizadas para a encapsulação de compostos bioativos}

Atualmente, várias técnicas são utilizadas para a encapsulação de compostos bioativos, como spray drying, spray cooling/chilling, extrusão, revestimento em leito fluidizado, coacervação, aprisionamento em lipossoma, complexação de inclusão, separação por centrífuga de suspensão, liofilização, co-cristalização e emulsificação (FANG; BHANDARI, 2010).

Além disso, a técnica de encapsulação pode ter diversas aplicações na indústria de alimentos, podendo assim, ser utilizada para estabilização de material encapsulado, controle de reações oxidativas, para a liberação controlada, para mascarar sabores, cores ou 
odores indesejáveis, prolongar a vida útil e proteger compostos de valor nutricional (MENEZES et al., 2013).

Em geral, três etapas estão envolvidas na encapsulação desses compostos: (I) a formação da parede em torno do material a ser encapsulado; (II) assegurar que um vazamento indesejado não ocorra; (III) assegurar que os materiais indesejados sejam mantidos fora (FANG; BHANDARI, 2010).

Nos últimos anos, as técnicas de encapsulação por aprisionamento em lipossomas, disco rotatório e coacervação, têm apresentado um rápido crescimento no interesse de pesquisadores e tecnólogos (GOUIN, 2004).

3.2 Principais materiais utilizados para a encapsulação de compostos bioativos

Um dos principais fatores que influenciam as propriedades funcionais das microcápsulas e, consequentemente, a estabilidade de compostos encapsulados é a natureza do material encapsulante (DESAI; PARK, 2005).

Para serem utilizados como encapsulantes os materiais devem atender aos seguintes requisitos: boas propriedades de formação de filme; baixa higroscopicidade; baixa viscosidade a altas concentrações de sólidos; sabor e odor suaves; fácil reconstituição; baixo custo e natureza semipermeável, apresentando morfologia esférica, envolta por uma resistente membrana sólida ou sólida/líquida, com um diâmetro variando de poucos mícrons a $1 \mathrm{~mm}$ (ANAL; SING, 2007; FOOD INGREDIENTS BRASIL, 2013).

Além disso, a escolha deste material deve ser baseada na não reatividade do material de revestimento com o material a ser encapsulado, na técnica que será utilizada para a formação das microcápsulas e no mecanismo ideal de liberação (SHAHIDI; HAN, 1993; FAVARO-TRINTADE; PINHO; ROCHA, 2008).

Nesse contexto, os carboidratos são os materiais mais utilizados para encapsulação, por sua capacidade de se ligar a compostos de sabor, além de sua diversidade e baixo custo. Como materiais encapsulantes para compostos bioativos podem ser utilizados proteínas, lipídeos e carboidratos (FOOD INGREDIENTS BRASIL, 2013).

\section{Encapsulação de compostos bioativos por coacervação complexa}

O conceito do processo de microencapsulação por coacervação complexa consiste, basicamente, na separação de fases de uma mistura de polieletrólitos a partir de uma solução e a deposição das partículas coloidais (ou seja, o material de matriz) sobre um núcleo ativo resultando na formação de um coacervado complexo (Figura 1) (AUGUSTIN; HEMAR, 2008).

Quando uma solução de biopolímeros de carga oposta é misturada, é formado um complexo. Assim, coacervados podem ser formados quando uma proteína a um $\mathrm{pH}$ abaixo do seu ponto isoelétrico (isto é, quando se carrega uma carga positiva) é misturada com um poliânion. Dessa forma, muitos fatores, incluindo o tipo de biopolímero (massa molar, flexibilidade e custo), o pH, a força iônica, a concentração e a relação entre os biopolímeros, afeta a força da interação entre estes e a natureza do complexo formado. Embora interações eletrostáticas sejam consideradas responsáveis pela interação entre os biopolímeros de carga oposta, interações hidrofóbicas e ligações de hidrogênio também podem contribuir de forma significativa para a formação do complexo (AUGUSTIN; HEMAR, 2008).

No entanto, um dos fatores que limitam a utilização de coacervados é a sua sensibilidade ao $\mathrm{pH}$ e à força iônica. Assim, para aumentar a robustez de coacervados, o invólucro formado pelos hidrocolóides pode então ser reticulado utilizando um agente de reticulação químico ou enzimático apropriado. O glutaraldeído é um agente de reticulação eficaz, mas existem problemas legais referentes à sua utilização. Nesse sentido, reticuladores enzimáticos, tais como a transglutaminase, são mais aceitáveis na indústria de alimentos e, recentemente, polifenóis extraídos de plantas têm sido utilizados para reticular coacervados à base de gelatina (GOUIN, 2004; AUGUSTIN; HEMAR, 2008). 


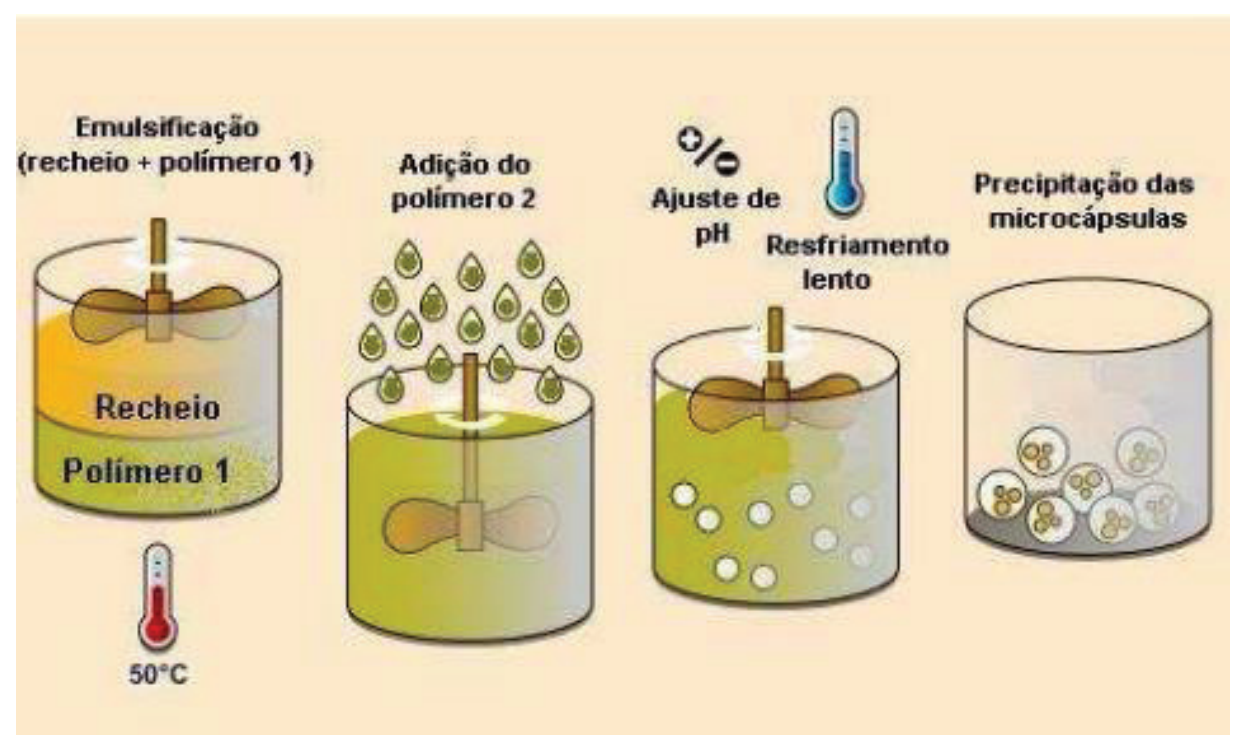

Figura 1: Representação esquemática da coacervação complexa Fonte: ARAÚJO (2011)

As microcápsulas produzidas por coacervação complexa podem ter tamanhos e características variados devido a alterações de $\mathrm{pH}$, concentração iônica, proporção de material encapsulante e do composto bioativo, bem como do tipo de material (DE VOS et al., 2010).

A coacervação é considerada uma tecnologia única e promissora de microencapsulação (Figura 2) devido à alta eficiência de encapsulação (até 99\%) e as possibilidades de liberação controlada com base no estresse mecânico, na temperatura ou liberação sustentada (GOUIN, 2004).

Além disso, o processo de coacervação complexa está associado aos benefícios que os alimentos podem oferecer, por preservar suas características funcionais, especialmente os alimentos de alto valor, os ingredientes funcionais instáveis, assim como na encapsulação de compostos bioativos. Dessa forma, a coacervação é geralmente utilizada na encapsulação de vários compostos bioativos, como óleos aromatizantes, óleos de peixe, nutrientes, vitaminas e enzimas (GOUIN, 2004; FANG; BHANDARI, 2010).
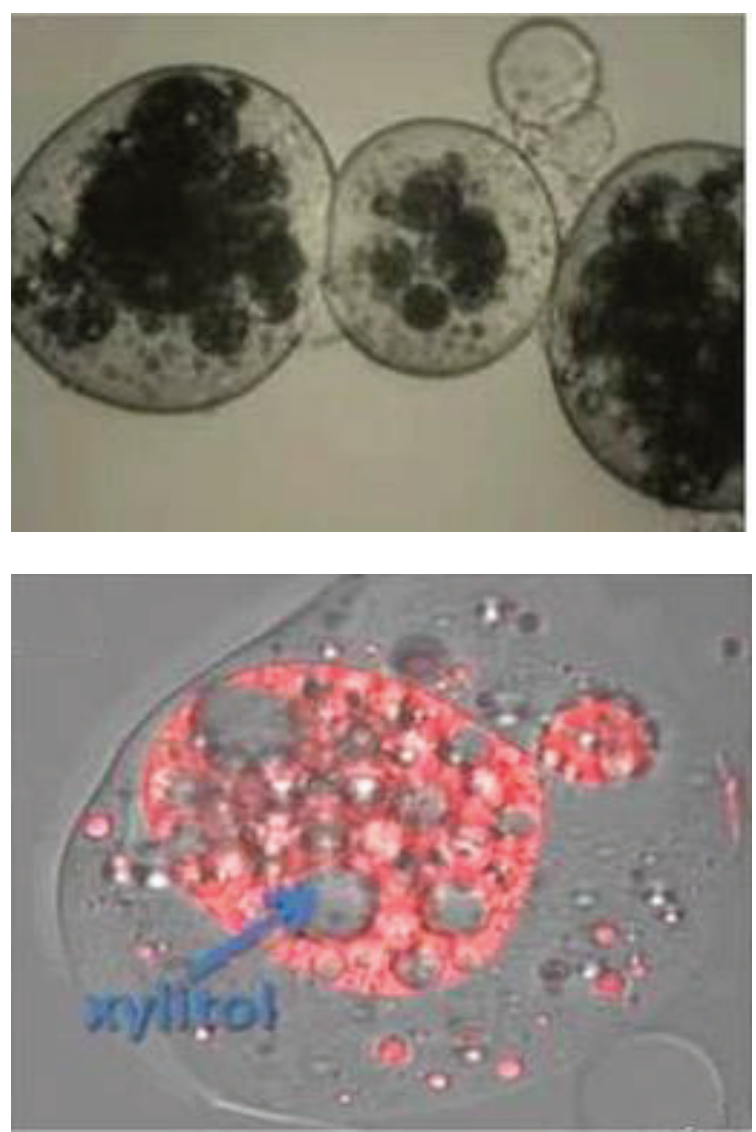

Figura 2: Microcápsulas de xilitol produzidas por coacervação complexa Fonte: SANTOS et al.(2015) 


\subsection{Aplicações da coacervação complexa para compostos biotivos}

Entre os materiais que podem ser encapsulados para aplicação na indústria alimentícia incluem-se ácidos, bases, óleos, vitaminas, sais, gases, aminoácidos, óleos essenciais, corantes, enzimas e microrganismos, sendo a maioria destes, compostos bioativos (FOOD INGREDIENTS BRASIL, 2013).

COMUNIAN et al. (2013) utilizaram a coacervação complexa com o objetivo de encapsular ácido ascórbico, caracterizar as cápsulas obtidas e determinar a estabilidade do material encapsulado. Para esse estudo foram realizadas diferentes composições para a produção das microcápsulas, variando as concentrações dos polímeros e do recheio. De acordo com os resultados obtidos, por meio de microscopia óptica, pode-se observar que as microcápsulas apresentaram-se arredondadas e multinucleadas. A técnica apresentou eficiência de encapsulação variando entre 97,33 $\pm 0,81$ e $99,57 \pm 0,32 \%$. Além disso, as microcápsulas apresentaram valores atividade de água menores que 0,6. Os valores para higroscopicidade

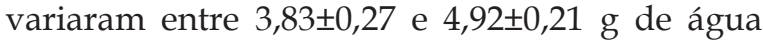
absorvida/100 g de pó, e os valores para solubilidade variaram entre 8,14 $\pm 0,51$ e $16,50 \pm 0,95 \%$. As microcápsulas apresentaram também diâmetros variando entre 51,67士2,77 e $83,82 \pm 4,14 \mu \mathrm{m}$. Em relação à estabilidade, após 30 dias a $20^{\circ} \mathrm{C}$, as microcápsulas ainda mantiveram 57 a $80 \%$ da concentração inicial de ácido ascórbico. À temperatura mais elevada de $37^{\circ} \mathrm{C}$, as microcápsulas mantiveram de 32 a $44 \%$ da concentração inicial de ácido ascórbico. Dessa forma, por meio da técnica de coacervação complexa é possível obter microcápsulas com um recheio hidrofílico. Além disso, os elevados valores obtidos na eficiência de encapsulação do ácido ascórbico comprovam a eficácia dessa técnica para a encapsulação.

A utilização da coacervação complexa também pode ser observada em estudo realizado por SANTOS et al. (2015). O objetivo deste estudo foi produzir e caracterizar microcápsulas de xilitol para utilização em alimentos, a fim de prolongar o poder adoçante e de refrigeração deste ingrediente. A coacervação complexa foi então empregada como o método de microencapsulação. Para isso, uma etapa prévia de emulsão dupla foi realizada devido à hidrofilicidade do xilitol. As microcápsulas obtidas foram caracterizadas em termos de tamanho de partícula e morfologia (microscopia óptica, confocal e eletrônica de varredura), solubilidade, isotermas de sorção, FTIR, eficiência de encapsulação e estudo de liberação. Neste estudo observou-se que as microcápsulas de xilitol apresentam características desejáveis para uso em alimentos, tais como tamanho de partícula inferior a $109 \mu \mathrm{m}$, baixa solubilidade e completa encapsulação do núcleo pelo material de parede. A eficiência de encapsulação variou de $31 \%$ a $71 \%$, sendo maior nos tratamentos com maiores concentrações de polímeros. Além disso, a liberação de mais de $70 \%$ de xilitol microencapsulado em saliva artificial ocorreu dentro de $20 \mathrm{~min}$.

Da mesma forma, a coacervação foi estudada por YANG et al. (2015). Este estudo teve como objetivo melhorar a estabilidade do óleo de sementes de papoula pela técnica de microencapsulação utilizando goma arábica e gelatina como materiais de parede. Microcápsulas de óleo de sementes de papoula foram preparadas com êxito por coacervação complexa seguido pelo método de spray drying. A caracterização das microcápsulas de óleo de sementes de papoula foi conduzida pelas técnicas de micrografia de varrimento electrônico (SEM), espectroscopia no infravermelho por transformada de Fourier (FTIR), calorimetria de varrimento diferencial (DSC), análise térmica (TGA) e difração de raiosX (DRX). A proporção de óleo em goma arábica/gelatina em microcápsulas foi avaliada e 1:3 foi selecionado como a proporção ótima. SEM mostrou que as microcápsulas exibiram forma esférica e distribuição regular. A eficiência de encapsulação (EE) foi de $76,8 \%$ e a capacidade de carga (LC) foi de 18,2\% para a formulação ideal. A oxidação de óleo de sementes de papoula encapsulado revelou que microcápsulas podem melhorar a estabilidade de armazenamento. As microcápsulas mostraram bom desempenho para o óleo de sementes de papoula, que pode ser utilizado nas indústrias de alimentos.

\section{Conclusões}

Diante do exposto, a técnica de coacervação complexa apresenta-se adequada a encapsulação de compostos bioativos, apresentando vantagens quando comparada a outras técnicas e uma alta eficiência de encapsulação, sendo, atualmente, amplamente utilizada na área industrial e possuindo grande potencial de exploração. 


\section{Agradecimentos}

A Coordenação de Aperfeiçoamento de Pessoal de Nível Superior (Capes).

\section{Referências}

ALVIM, I.D.; GROSSO, C.R.F. Microparticles obtained by complex coacervation: influence of the type ofreticulation and the drying process on the release of the core material. Ciênc. Tecnol. Aliment., Campinas, v. 30, cap. 4, p. 1069-1076, out.-dez. 2010.

ANAL, A.K.; SINGH, K. Recents advances in microencapsulation of probiotics for industrial applications and targeted delivery. Trends in Food Science \& Technology, v.18, p.240-251, 2007.

ARAÚJO, A.L. Microencapsulação do ferro através da técnica de coacervação complexa. $52 \mathrm{f}$. Universidade Federal do Rio Grande do Sul, Porto Alegre, 2011.

ASSIS, L.M.; ZAVAREZE, E.R.; PRENTICEHERNÁNDEZ, C.; SOUZA-SOARES, L.A. Características de nanopartículas e potenciais aplicações em alimentos. Brazilian J Food Technol, v. 15, p. 99- 109, 2012.

BETORET, E.; BETORET, N.; VIDAL, D.; FITO, P. Functional foods development: Trends and Technologies. Trends in Food Science \& Technology, v. 22, p. 498-508, 2011.

BRASIL. Agência Nacional de Vigilância Sanitária - ANVISA. Alimentos com Alegações de propriedades funcionais e ou de saúde Alegações de propriedades funcionais aprovadas. Diário Oficial da União, Brasília, DF, 2008. Disponível em http://portal.anvisa.gov.br/wps/content/Anvis a+Portal/Anvisa/Inicio/Alimentos/Assuntos+d e+Interesse/Alimentos+Com+Alegacoes+de+Pr opriedades+Funcionais+e+ou+de+Saude/Alega coes+de+propriedade+funcional+aprovadas. Acesso em: 08/09/2015.

CHAMPAGNE C.P.; FUSTIER P. Microencapsulation for the improved delivery of bioactive compounds into foods. Current Opinion in Biotechnology, v.18, p.184-190, 2007.
COMUNIAN, T. A.; THOMAZINI, M.; ALVES, A. J. G.; MATOS JUNIOR, F. E.; BALIEIRO,J. C. C.; FAVARO-TRINDADE, C. S. Microencapsulation of ascorbic acid by complex coacervation: Protection and controlled release. Food Research International, v. 52, p. 373-379, 2013.

COZZOLINO, S. Nutracêuticos: o que significa? Associação Brasileira para Estudo da Obesidade - ABESO, v. 55, fevereiro, 2012.

DESAI, K. G. H., PARK, H. J. (2005). Recent Developments in Microencapsulation of Food Ingredients. Drying Technology, v. 23, p. 13611394, 2005.

DE VOS, P.; FAAS, M. M.; SPASOJEVIC, M.; SIKKEMA, J. Encapsulation for preservation of functionality and targeted delivery of bioactive food components. International Dairy Journal, v. 20 (4), p. 292-302, 2010.

DONSİ, F.; SESSA, M.; MEDIOUNI, H.; MGAIDI, A.; FERRARI, G. Encapsulation of bioactive compounds in nanoemulsionbased delivery systems. Procedia Food Science, v. 1, p. 1666 - 1671, 2011.

FANG, Z.; BHANDARI, B. Encapsulation of polyphenols - a review. Trends in Food Science \& Technology, v. 21, p. 510-523, 2010.

FAVARO-TRINDADE, C. S.; PINHO. S. C.; ROCHA, G. A. Revisão: Microencapsulação de ingredientes alimentícios. Brazilian Journal of Food Technololy, v. 11, n. 2, p.103-112, 2008.

FOOD INGREDIENTS BRASIL. A microencapsulação a serviço da indústria alimentícia. N²5, 2013.

GOUIN, S. Microencapsulation: industrial appraisal of existing Technologies and trends. Trends in Food Science \& Technology, v. 15, p. 330-347, 2004.

KRIS-ETHERTON, P. M.; HECKER, K.D.; BONANOME, A.; COVAL, S.M.; BINKOSKI, A.E.; HILPERT, K. F.; GRIEL, A.E.; ETHERTON, T.D. Bioactive Compounds in Foods: Their Role in the Prevention of Cardiovascular Disease and Cancer. The American Journal of Medicine, v. 113, p. 71S-88S, 2002. 
MALATAINS, A.; JONES, O. G.; MCCLEMENTS, D. J. Structured biopolymerbased delivery systems for encapsulation, protection, and release of lipophilic compounds. Food Hydrocolloids, v.25, n.8, p.1865-1880, 2011.

MENEZES, C. R.; BARIN, J.S.; CICHOSKI, A.J.; ZEPKA, L.Q.; JACOB-LOPES, E.; FRIES, L.L.M.; TERRA, N.N. Microencapsulação de probióticos: avanços e perspectivas. Ciência Rural, v. 43, n.7, p.1309-1316, 2013.

PENINGTON, J.A.T. Food Composition Databases for Bioactive Food Components. Journal of Food Composition and Analysis, v. 15, p. 419-434, 2002.

\section{SANTOS, M.G.; BOZZA, F.T.; THOMAZINI, M.; FAVARO-TRINDADE, C.S.} Microencapsulation of xylitol by double emulsion followed by complex coacervation. Food Chemistry, v. 171, p. 32-39, 2015.

SAUVANT, P.; CANSELL, M.; SASSI, A.H.; ATGIÉ, C. Vitamin A enrichment: Caution with encapsulation strategies used for food applications. Food Research International, v. 46, p. 469-479, 2012.

SECOLIN, V.A. Microencapsulação de compostos bioativos de Camellia sinensis em sistemas lipídicos por spray-drying. $113 \mathrm{f}$. Dissertação (Mestrado), Faculdade de Ciências Farmacêuticas de Ribeirão Preto - Universidade de São Paulo, Ribeirão Preto, 2014.

SHAHIDI, F.; HAN, X. Encapsulation of food ingredients. Critical review in food science and nutrition, v.33, n.6, p.501-547. 1993.

SHOJI, A.S.; OLIVEIRA, A.C.; BALIEIRO, J.C.C.; FREITAS, O.; THOMAZINI, M.; HEINEMANN, R.J.B.; OKURO, P.K.; FAVAROTRINDADE, C. S. Viability of L. acidophilus microcapsules and their application to buffalo milk yoghurt. Food and Bioproducts Processing, v. 91, p. 83-88, 2013.

SIEGRIST, M.; COUSIN, M-E.; KASTENHOLZ, H.; WIEK, A. Public acceptance of nanotechnology foods and food packaging: The influence of affect and trust. Appetite, v. 49, p. 459-466, 2007.
YANG, X.; GAO, N.; HU, L.; LI, J.; SUN, Y. Development and evaluation of novel microcapsules containing poppy-seed oil using complex coacervation. Journal of Food Engineering, v. 161, p. 87-93, 2015. 